\title{
Influence of working pressure and lasing energy of Al plasma in
}

\section{laser-induced breakdown spectroscopy}

\section{Marieam Ghreeb Jasim and Qusay Adnan Abbas}

Department of Physics, College of Science, University of Baghdad, Baghdad, Iraq

E-mail: Qusayiraqi@yahoo.com

\begin{abstract}
Aluminum plasma was generated by the irradiation of the target with Nd: YAG laser operated at a wavelength of $1064 \mathrm{~nm}$. The effect of laser power density and the working pressure on spectral lines generating by laser ablation, were detected by using optical spectroscopy. The electron density was measured using the Stark broadening of aluminum lines and the electron temperature by Boltzmann plot method it is one of the methods that are used. The electron temperature $T_{e}$, electron density $n_{e}$, plasma frequency $\omega_{p}$ and Debye length $\lambda_{D}$ increased with increasing the laser peak power. The electron temperature decrease with increasing gas pressure.
\end{abstract}

\author{
Key words \\ LIBS, plasma \\ characteristics, OES, \\ electron temperature, \\ electron density.
}

Article info.

Received: Aug. 2018

Accepted: Oct. 2018

Published: Mar. 2019

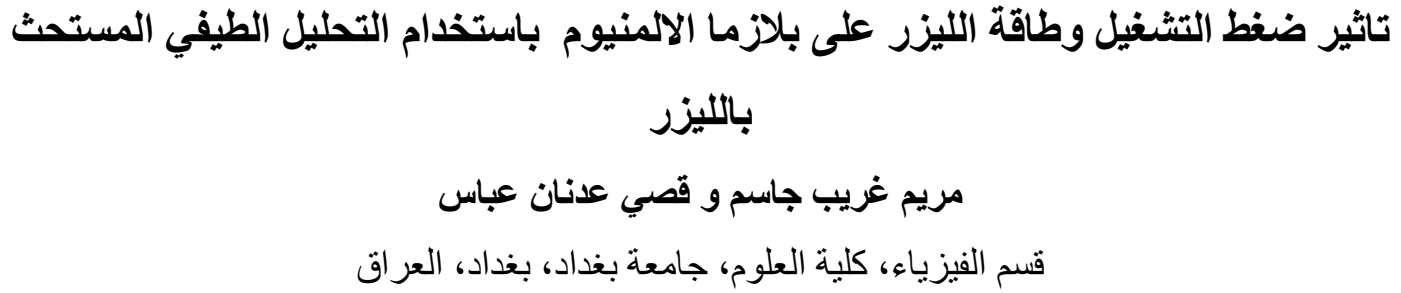

\section{Introduction}

LIBS is an atomic emission spectrum analysis technique. Which is a high pulsed laser power density which is localized onto a small target volume leading to a breakdown of analytical into ions and free electrons, resulting a plasma identify by both continuum and atomic emission [1]. The parameters of the Laser-generated plasma is progress quickly and are strongly related on irradiation conditions like Intensity of laser incident on a surface of the target and pulse laser duration, the wavelength of the laser, the spot size of radiance, gas ambient installation, and ambient pressure, which are temporary in nature [2, 3]. Optical Emission Spectroscopy (OES) has been used for years to determine the plasma parameters such as electron density 
$\left(n_{e}\right)$ and electron temperature $\left(T_{e}\right)$, Debye length $\left(\lambda_{\mathrm{D}}\right)$ and plasma frequency $\left(f_{D}\right)[4]$. Plasma diagnostic method can be done through an account of the plasma electron temperature $\left(T_{e}\right)$ and density $\left(n_{e}\right)$. The strength of different distribution functions describing the plasma state determines by the temperature, while the state of thermo- dynamical equilibrium of the plasma specifies by the electron density [5]. For the calculation of electron temperature the Boltzmann plot method it is one of the simplest methods that are used $[6,7]$.

$\ln \left(\lambda_{\mathrm{mn}} \mathrm{I}_{\mathrm{mn}} / \mathrm{g}_{\mathrm{m}} \mathrm{A}_{\mathrm{mn}}\right)=-\mathrm{E}_{\mathrm{m}} / \mathrm{KT}_{\mathrm{e}}+\ln (\mathrm{N}$ $(\mathrm{T}) / \mathrm{U}(\mathrm{T}))$

where: $\lambda_{\mathrm{mn}}$ is wavelength of the spectral line, $I_{m n}$ intensity of the spectral line. $A_{m n}$ is the transition probability of upper (m) and lower (n) energy states. $E_{m}$ and $g_{m}$ are the upper states (m) energy and statistical weight Te is the electron temperature, $\mathrm{K}$ is the Boltzmann constant, $\mathrm{N}(\mathrm{T})$ and $\mathrm{U}(\mathrm{T})$ are the total number density and partition function.

The Stark broadening effect was used to calculate the electron density requires a line which is free from selfabsorption [8]:

$n_{e}=\left[\frac{\Delta \lambda}{2 \omega_{s}}\right] N_{r}$

$\omega_{s}$ : is the theoretical line full width Stark broadening parameter, calculated at the same reference electron density $N_{r} \approx 10^{17} \mathrm{~cm}^{-3}$. Plasma frequency can be given as[9]:

$\omega_{p=}\left(n_{e} e^{2} / m_{e} \varepsilon_{0}\right)^{1 / 2}$

where $\varepsilon_{0}$ is the Permittivity of free space, $m_{e}$ is the electron mass, $n_{e}$ is the electron number density and $e$ is electron charge.

Debye's length can be calculated by the formula [9]:

$\lambda_{D}=\left[\frac{\varepsilon_{o} K_{B} T_{e}}{n_{e} e^{2}}\right]^{\frac{1}{2}} \cong 7.43 \times 10^{2}\left(\frac{T_{e}(e V)}{n_{e}}\right)^{\frac{1}{2}}$

where: $k_{B}$ is Boltzmann's constant, $T_{e}$ is the plasma temperature, $\mathrm{e}$ is the electron charge and $n_{e}$ is the electron density.

\section{Experimental part}

Fig.1 illustrates the experimental setup of LIBS system used for the detection of the spectral lines of the laser-generated Al plasma, target was bombarded by Nd: YAG pulse laser ( $9 \mathrm{~ns}$ duration, $6 \mathrm{~Hz}$ repetition frequency, and fundamental wavelength of $1064 \mathrm{~nm}$ ) and laser pulse energy ranging from $100 \mathrm{~mW}$ to $400 \mathrm{~mW}$ on target surface, at an angle of $45^{\circ}$. To focus the laser on the target surface we used the convex lens with a focal length equal to $10 \mathrm{~cm}$. The circularly shaped sheet of the aluminum target with diameter $3 \mathrm{~cm}$ is placed inside a vacuum chamber. The chamber was filled up with Argon gas at a pressure (0.2 and 0.4 Torr). The vacuum chamber made of a cylindrical stainless steel tube. The two ends closed by Pyrex windows, by two stainless steel flanges, and with small quartz window fixed in it is center, that allows the laser pulse to shoot the $\mathrm{Al}$ target. Two small pipes connected to pumping systems, while the other was used to deliver the argon gas with purity $(99.9 \%)$. 


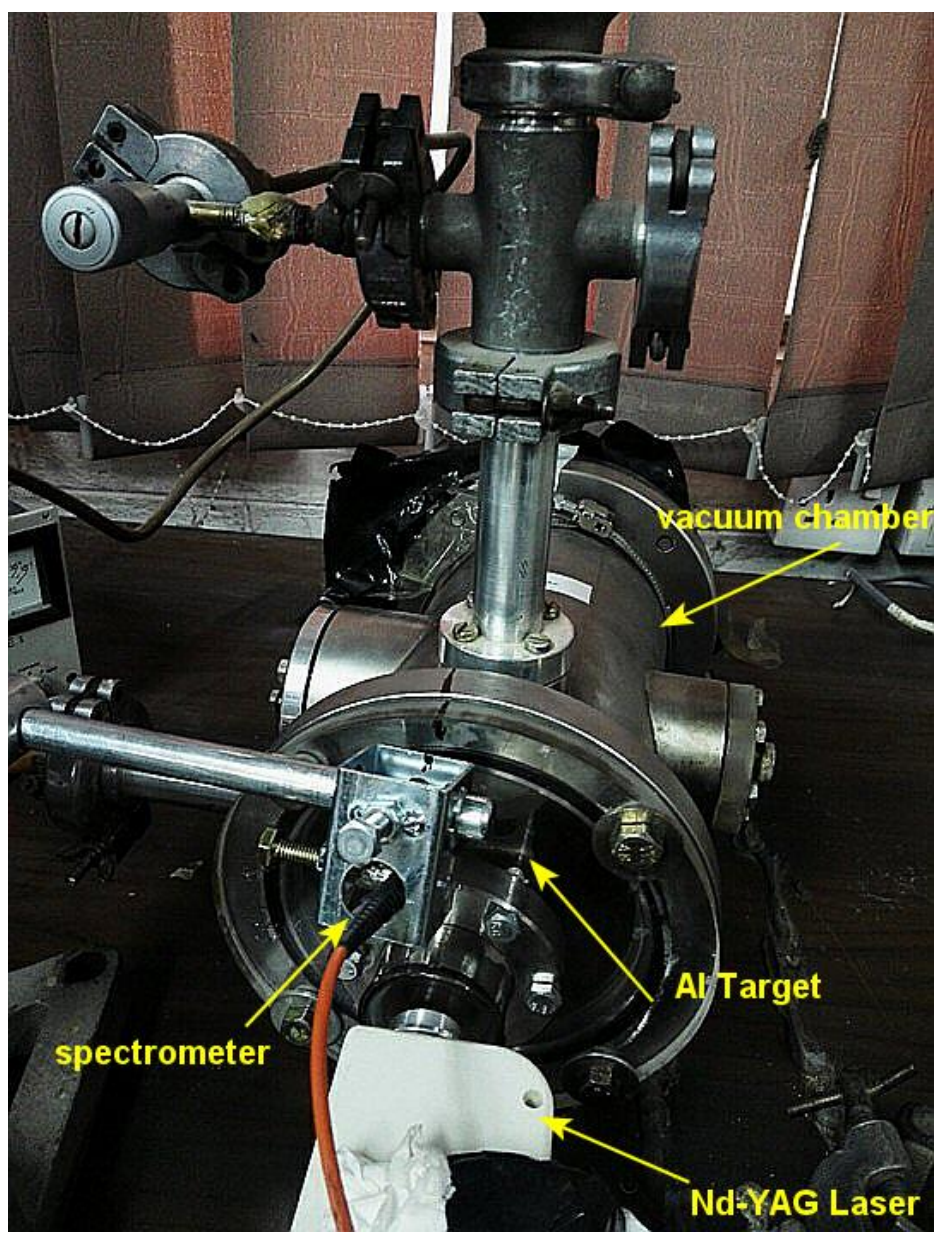

Fig.1: Experimental set up of the LIBS system.

\section{Results and discussions}

The Al plasma was produced by the laser interaction with $\mathrm{Al}$ target using Q-switched $\mathrm{Nd}$ : YAG in a vacuum. A spectrum consists of a number of characteristic spectral lines of particular atoms and ions. The increase in the pulse laser power density will increase its absorption in the plasma resulting in more ablation which results in the increase of the spectral line intensities of the plasma emission. The value of $T_{e}$ is obtained using the Boltzmann plot method (Eq.(1)), this requires peaks that originated from the same atomic species and the same ionization stage with data from NIST site, where the electron temperature equal to the invert of the slope of the fitting line (the slope of fitted line equals to $\left(-1 / k_{B} \mathrm{~T}\right)$. Fig. 2 and 3 show a Boltzmann plot by plotting a graph between $\operatorname{Ln}\left(\frac{I_{j i} \lambda_{j i}}{h c g_{j} A_{j i}}\right)$ as a function of $E_{k}$. The electron temperature of $\mathrm{Al}$ plasma increases with increasing laser power from (100 to $400 \mathrm{~mW}$ ), electron temperature decrease with increasing working pressure. 


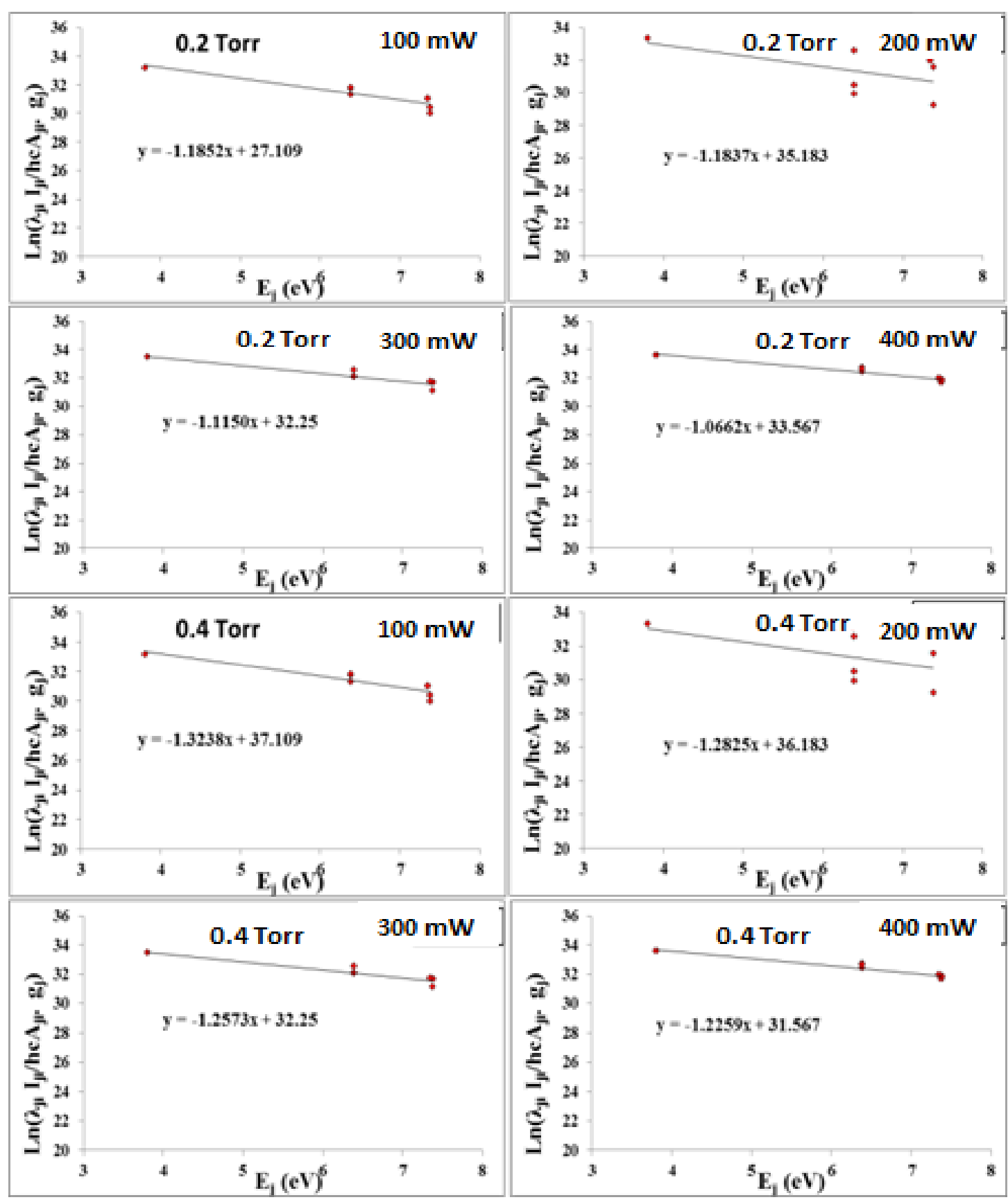

Fig. 2: Boltzmann plot for Al target with different laser peak power in 0.2 and 0.4 Torr at $1064 \mathrm{~nm}$. 


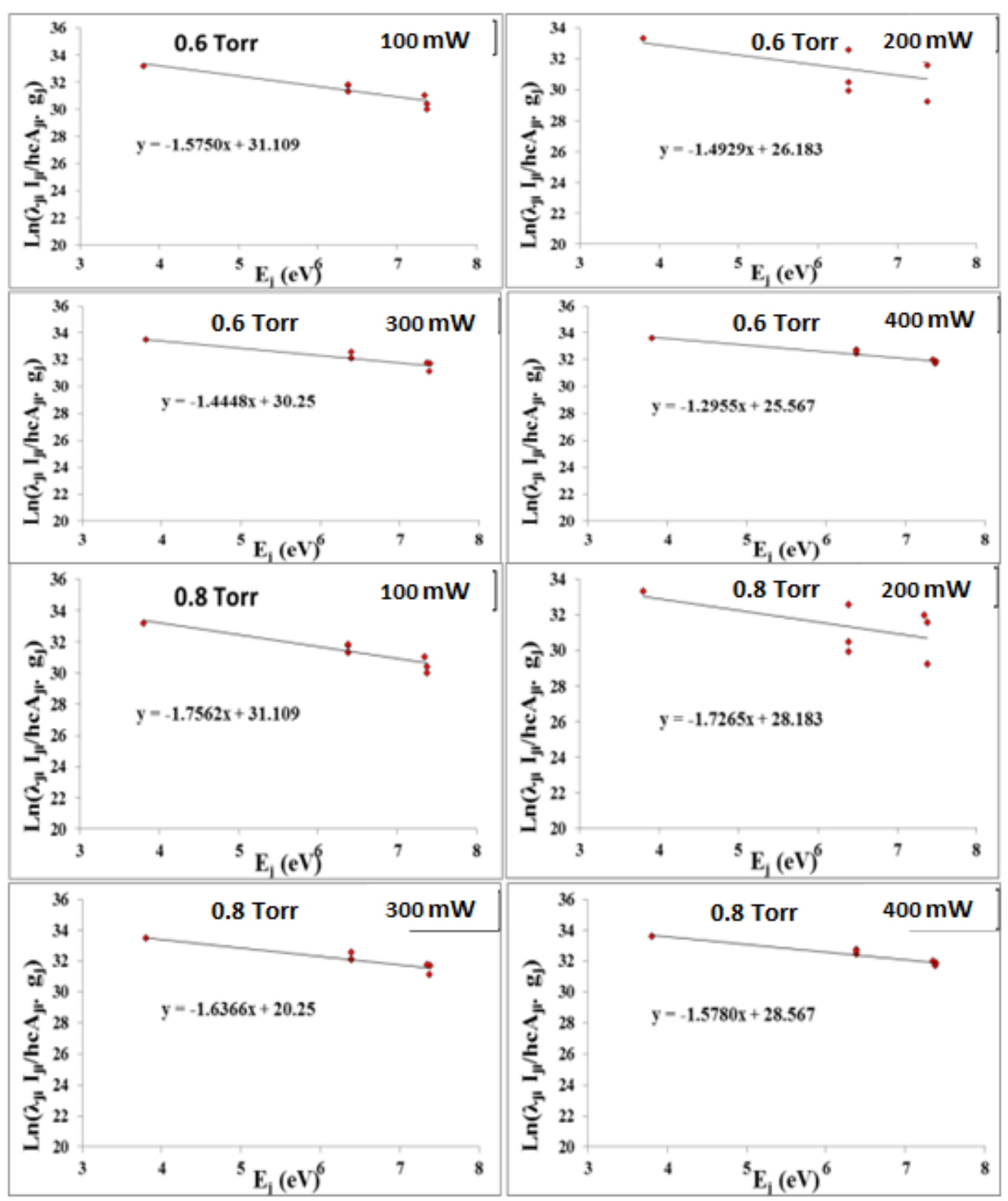

Fig. 3: Boltzmann plot for Al target with different laser peak power in 0.6 and 0.8 Torr at $1064 \mathrm{~nm}$.

Fig. 4 shows the variation of $\mathrm{T}_{\mathrm{e}}$ and $\mathrm{n}_{\mathrm{e}}$ with laser power density. The results of these figures illustrated that the increase of laser power density lead to an increase of electron temperature and the electron density, this is due to the absorption of the laser photon by the plasma [10]. The increasing of $n_{e}$ with increasing of laser power density and working pressure attributed to the increase of electron collisions with the ambient gas. 


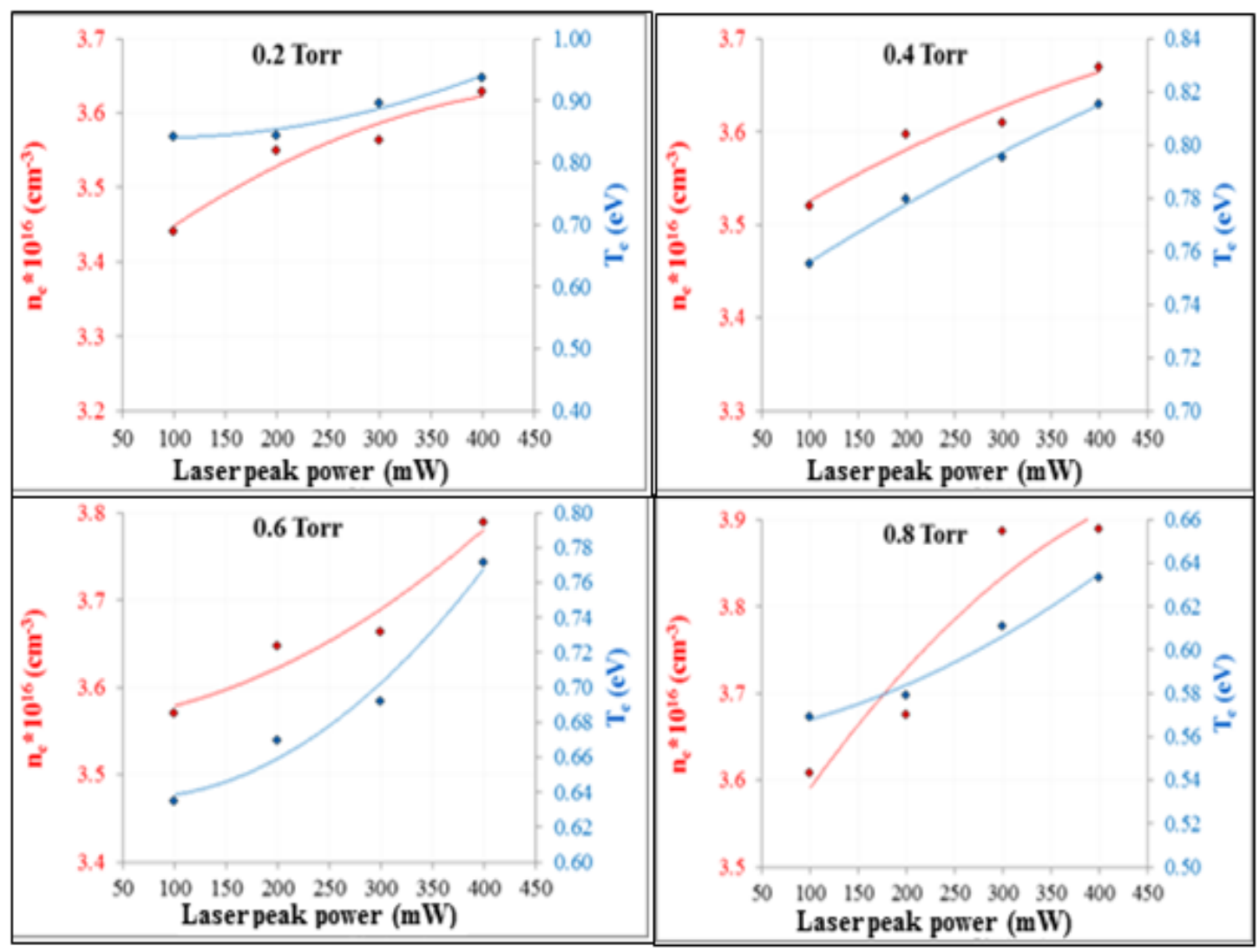

Fig.4: The variation of $T e$ and $n_{e}$ versus the laser peak power.

Table 1 shows the values of electron temperature $\left(\mathrm{T}_{\mathrm{e}}\right)$, electron density $\left(\mathrm{n}_{\mathrm{e}}\right)$, Debye length $\left(\lambda_{\mathrm{D}}\right)$ by using Eq. (4), plasma frequency $\left(\omega_{p}\right)$ using eq. 3 for $\mathrm{Al}$ targets at different laser pulse energies (100 to 400) $\mathrm{mj}$ with different working pressures $(0.2$ to 0.8$)$ Torr. The values of plasma frequency increase because of the dependence of plasma frequency on the dens ity of electrons $\left(\mathrm{n}_{\mathrm{e}}\right)^{1 / 2}$, We can also notice that the plasma frequency increases with the increase of the laser energies. Also the, Debye length increase because Debye length depends on plasma temperature and plasma density [11]. 
Table 1: Plasma parameters for Al target at (1064 $\mathrm{nm})$ in vacuum with different laser energies and different working pressure.

\begin{tabular}{|c|c|c|c|c|c|}
\hline \multirow{5}{*}{$\begin{array}{l}\tilde{D} \\
\tilde{o} \\
\tilde{o}\end{array}$} & $\begin{array}{l}\text { Laser peak } \\
\text { power }(\mathrm{mW})\end{array}$ & Te $(\mathrm{eV})$ & $n_{e^{*} * 10^{16}}\left(\mathrm{~cm}^{-3}\right)$ & $\omega p * 10^{12}(\mathrm{~Hz})$ & $\lambda_{\mathrm{D}} * 10^{-5}(\mathrm{~cm})$ \\
\hline & 100 & 0.7837 & 3.1383 & 1.5908 & 0.3713 \\
\hline & 200 & 0.8007 & 3.2411 & 1.6166 & 0.3693 \\
\hline & 300 & 0.8021 & 3.3319 & 1.6391 & 0.3645 \\
\hline & 400 & 0.8473 & 3.4358 & 1.6645 & 0.3697 \\
\hline \multirow{5}{*}{$\stackrel{\square}{\stackrel{0}{0}}$} & $\begin{array}{c}\text { Laser peak } \\
\text { power }(\mathrm{mW})\end{array}$ & Te (eV) & $\mathrm{n}_{\mathrm{e}^{*}} 10^{16}\left(\mathrm{~cm}^{-3}\right)$ & $\omega p * 10^{12}(\mathrm{~Hz})$ & $\lambda_{\mathrm{D}} * 10^{-5}(\mathrm{~cm})$ \\
\hline & 100 & 0.7041 & 3.1988 & 1.6060 & 0.3486 \\
\hline & 200 & 0.7360 & 3.2980 & 1.6308 & 0.3510 \\
\hline & 300 & 0.7509 & 3.4251 & 1.6619 & 0.3479 \\
\hline & 400 & 0.7629 & 3.5261 & 1.6862 & 0.3456 \\
\hline \multirow{5}{*}{ 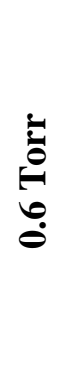 } & $\begin{array}{l}\text { Laser peak } \\
\text { power }(\mathrm{mW})\end{array}$ & Te $(\mathrm{eV})$ & $\mathrm{n}_{\mathrm{e}^{*}} 10^{16}\left(\mathrm{~cm}^{-3}\right)$ & $\omega p * 10^{12}(\mathrm{~Hz})$ & $\lambda_{\mathrm{D}} * 10^{-5}(\mathrm{~cm})$ \\
\hline & 100 & 0.5509 & 3.2455 & 1.6177 & 0.3061 \\
\hline & 200 & 0.6017 & 3.3043 & 1.6323 & 0.3170 \\
\hline & 300 & 0.6403 & 3.4521 & 1.6684 & 0.3200 \\
\hline & 400 & 0.6912 & 3.5594 & 1.6942 & 0.3274 \\
\hline \multirow{5}{*}{$\underset{0}{0}$} & $\begin{array}{c}\text { Laser peak } \\
\text { power }(\mathrm{mW})\end{array}$ & Te $(\mathrm{eV})$ & $n_{e^{*}} 10^{16}\left(\mathrm{~cm}^{-3}\right)$ & $\omega p * 10^{12}(\mathrm{~Hz})$ & $\lambda_{\mathrm{D}} * 10^{-5}(\mathrm{~cm})$ \\
\hline & 100 & 0.5312 & 3.3776 & 1.6503 & 0.2946 \\
\hline & 200 & 0.5593 & 3.3909 & 1.6536 & 0.3017 \\
\hline & 300 & 0.5635 & 3.5630 & 1.6950 & 0.2954 \\
\hline & 400 & 0.5701 & 3.6307 & 1.7110 & 0.2944 \\
\hline
\end{tabular}

\section{Conclusions}

The plasma parameters such as temperature and number density are found to increase with the laser irradiance. It is inferred that at first stage the laser vapor interaction is largely due to the inverse bremsstrahlung (IB) process. And the electron temperature decrease with increasing working pressure from 0.2 Torr to 0.8 Torr, The increasing of inelastic collisions of an electron with $\mathrm{Ar}$ atoms with increasing of gas pressure is responsible for decreasing of $\mathrm{T}_{e}$ with increasing of pressure, the electron density increase with increasing the working pressure.

\section{References}

[1] J. Feng, Z. Wang, Z. Li, W. Ni, Spectrochim. Acta - Part B At. Spectrosc., 65, 7 (2010) 549-556.

[2] V. N. Rai, H. Zhang, F. Y. Yueh, J. P. Singh, A. Kumar, Appl. Opt., 42, 18 (2003) 3662-3669.

[3] S. S. Harilal, C. V. Bindhu, M. S. 
Tillack, F. Najmabadi, A. C. Gaeris, J. Appl. Phys., 93, 5 (2003) 2380-2388.

[4] Ulf Saalmann and Jan-Michael Rost, Phys. Rev. Lett., 89, 14 (2002) 143401_1-143404.

[5] A. M. El Sherbini, World J. Nano Sci. Eng., 2, December (2012) 206212.

[6] J. A. Aguilera and C. Aragón, Spectrochim. Acta-Part B At. Spectrosc., 59, 12 (2004) 1861-1876.

[7] S. Waheed, Shazia Bashir, Asadullah Dawood, Safia Anjum, Mahreen Akram, Asma Hayat, Saba Amin, Ali Zaheer, International Journal for Light and Electron Optics,
International Journal for Light and Electron Optics, 140 (2017) 536-544.

[8] A. M. El Sherbini, Opt. Photonics J., 2, 4 (2012) 278-285.

[9] R. K. Tyagi, R. S. Pandey, A. Kumar, K. K. Srivastava, Int. J. Eng. Sci. Technol., 3, 8 (2011) 168-176. [10] M. V. Allmen and A. Blatter, Springer-Verlag, Berlin, 2nd ed, (1995).

[11] Bhatti, K. A., Khaleeq Rahman, M.Rafique, M. S.Shahzad, M. I. Latif, A. Parveen, Vacuum, 82, 11 (2008) 1157-1161. 